\begin{abstract}
Modern technologies can aid working processes as well as provide individuals with an opportunity to connect and form interpersonal relationships. However, they can also create a context for displaced aggression. In this study, we examine whether people experiencing work stressors may engage in online antisocial behavioral as a means of venting their negative emotions. Specifically, we investigate whether experiencing stressors at work fuels anger in the private context and whether this anger triggers subsequent displaced aggression in the form of antisocial online behavior (AOB) throughout the evening. Additionally, we examine the crossover of anger to AOB in couples in their private context. We conducted a diary study amongst 95 dual-earner couples, twice a day, during five consecutive working days. Results confirmed that men's daily work stressors spilled over to their private context in the form of anger after work and AOB throughout the evening. No crossover effects were found from their partner. For women, a crossover effect was found of their partner's work stressors and anger on their own AOB. These results demonstrate gender differences in displaced online aggression.
\end{abstract}

Keywords: displaced online aggression; work stress; antisocial online behavior; emotions; diary study; cyberbullying; 


\section{YOU WOULDN'T LIKE ME WHEN I'M ANGRY: A DAILY DIARY STUDY OF DISPLACED ONLINE AGGRESSION IN DUAL-EARNER COUPLES}

The use of Information and Communication Technologies (ICTs) has grown exponentially over the past decades and has forever changed the global landscape (Chinn \& Fairlie, 2010). Today, modern technologies impact almost all aspects of our life-work and personal—and are an inherent part of social relationships (Korunka \& Hoonakker, 2014). Organisations have readily adopted ICTs to support and improve their business processes (Hunton et al., 2003) and increase their productivity, effectiveness, and efficiency (Bharadwaj, 2000). However, despite various advantages alongside the many possibilities ICTs have to offer (e.g., efficient and boundless communication), scholars and practitioners alike have recently become aware of their dark side as well.

It has become evident in the past few years that the online environment often serves as a platform for interpersonal mistreatment. Every day, millions of negative online comments are posted on different social media platforms (Pfeffer et al., 2014). The online environment has become characterized by a vast array of negative behaviors, such as trolling, flaming, hate speech, abuse and bullying (Vranjes et al., 2020). Deliberately offensive and discriminatory online content has become routinized on certain platforms, often as a means to seek attention and evoke reaction (Bernstein et al., 2011). Furthermore, this type of hostility has been observed both in anonymous online communication (Lapidot-Lefler \& Barak, 2012) and in public exchanges (Ybarra et al., 2006). This is a serious problem because it can cause profound damage, in the form of mental strain, reduced emotional well-being, reduced health, and depressive symptoms (D'Cruz \& Noronha, 2014; Farley et al, 2015; Muhonen et al., 2017) to those individuals who are on the receiving end of this behavior. 
Previous studies in the school context have suggested that online platforms may serve as context for adolescents to vent their negative emotions and engage in negative online behaviors (Erreygers et al., 2018). The fact that online platforms lend itself to a more overt display of negative behavior can be attributed to the deindividuation effect (Festinger et al., 1952), which makes people less aware of themselves and the existing social norms when they feel anonymous (Dooley et al., 2009), and to the disinhibition effect (Suler, 2004), which makes people act differently online compared to how they would act in a face-to-face context. However, adolescents are not the only ones engaging in negative online behaviors. Studies show that antisocial online behavior (AOB) in working adults - which we define as all behavior committed online that falls outside the normative consensus of what is socially acceptable (based on Catalano \& Hawkins, 1996) - is a widely occurring issue (Coyne et al., 2017; Forssell, 2016; Gardner et al., 2016; Lim \& Teo, 2009; Privitera \& Campbell, 2009). Despite these observations, we still know very little about when and why working adults engage in $\mathrm{AOB}$.

Building on the theory of displaced aggression (Dollard et al., 1939) and on the notion of deindividuation and disinhibition online, we argue that working individuals may engage in AOB as a form of displaced aggression fueled by the experience of daily work stressors and anger. Working individuals spend a considerable time of their lives at work. Although work fulfills an important function in people's lives (Morse \& Weiss, 1955), the work environment can be a significant source of stressors and negative emotions as well (Ohly \& Schmitt, 2013). Given the importance of maintaining a positive image at work and preserving one's job (Bolino, 1999), it is plausible that people may abstain from expressing some of their workrelated frustration in the workplace. In such cases, the deindividuation and disinhibition effect may make the online environment a perfect context for letting off the steam. In this study, we examine work stressors as a potential source of negative emotions and subsequent antisocial 
online behavior (AOB) in dual-earner couples. In addition, we test whether stressor-induced anger of a person can cross over and lead to more AOB in their partner. In other words, in this study we test whether both stressor- and partner-induced anger is associated with more AOB in working individuals. Given the fluctuating nature of stress and emotions (Lazarus, 1991; Lazarus \& Folkman, 1984), we apply a daily diary design to test daily, within-person processes that lead to the enactment of AOB.

The contributions of this study are threefold. Discrete emotions, such as anger, are hot emotions with short-term effects that dissipate over time (Lazarus \& Folkman, 1984) leading authors to emphasize the need for measuring discrete emotions and their outcomes dynamically and using short time lags (Payne, 2001). Yet, the gross of studies on the relationship between emotions and employee aggression are either cross-sectional or apply longitudinal designs with time lags of several months (e.g., Fida et al., 2015; Glaso et al., 2010; Mignonac \& Herrbach, 2004; Vranjes et al., 2018). We therefore contribute to the literature on employee aggression and emotions in the workplace by investigating employee aggression as it occurs, increasing the accuracy and validity of our findings. Second, while much attention in the workplace literature has been given to the consequences of online aggression on targets (e.g., Farley et al., 2015; Kowalski \& Toth, 2018), far less is known about factors that can drive individuals to engage in such behavior. This study increases our understanding of processes contributing to online aggression, by suggesting that employees may displace their work-related stress online. Finally, this study contributes to the literature on the spillover and crossover of stress. Namely, while other studies on work spillover have focused on outcomes such as wellbeing, affect, and job and martial satisfaction (e.g., Bakker et al., 2011; Ferguson et al., 2015; Liu et al., 2016; Sonnentag \& Binnewies, 2013), this study highlights the possibility of a different type of spillover - namely, spillover of work-related aggression to the virtual context. By doing so, we demonstrate that the impersonal nature of 
the online environment may make it a suitable context for the displacement of people's frustrations. Furthermore, we show just how far-reaching the spillover of work stress can be, affecting not only employees, but the online community as well. Furthermore, while the current crossover literature recognizes that spouses influence each other not only directly (e.g., transfer of emotions) but also indirectly (e.g., affecting each other's sleep due to stress) (Westman, 2001), such indirect crossover effects have rarely been tested. In this study we contribute to the crossover literature by demonstrating an indirect crossover of an employee's stressor-induced anger after work to their partner's AOB throughout the evening.

\section{THEORETICAL BACKGROUND AND HYPOTHESES}

\section{Work Stressors and Negative Emotions}

Work stressors are environmental factors that decrease the health and well-being of workers (Bliese et al., 2017; Hurrell et al.,1998). They are either objective features of the work environment that most people perceive as stressful, or they are features that are perceived as stressful by certain individuals. Perceived stressors are of particular interest in organizational research because they are most clearly linked to emotional responses (Spector \& Fox, 2005). Work stressors are very frustrating for employees (Bensimon, 1997) and can therefore evoke an array of negative emotions (Dollard et al., 1939; Lazarus \& Folkman, 1984; Spector \& Fox, 2005; Weiss \& Cropanzano, 1996). In that regard, anger is a frequently experienced emotion in the workplace (Fitness, 2000). In her study on workplace anger, Fitness (2000) found a range of anger-eliciting events at work, including unjust treatment, immoral behavior, job incompetence, and public humiliation. Other studies also find an association between anger and different work stressors, including work pressure, organizational injustice, poor interpersonal relationships, and others' and own underperformance (Ayoko et al, 2012; Gianakos, 2002; Hoggan \& Dollard, 2007; Mawritz et 
al., 2014; Weiss et al., 1999). Furthermore, according to Gianakos (2002), such anger-evoking events impact both men and women equally.

Anger is said to be a negative, active emotion (Russell, 1980) that arises as a consequence of a situation threatening a person's attainment of desired goals (Lazarus, 1991). In addition to that, anger mobilizes energy for confrontation and drives people to react to the perceived threat (Moons et al., 2010). Work stressors can not only frustrate individual goal attainment at work (i.e., good performance and interpersonal functioning), but can also be attributed to a wrongdoing on someone else's behalf, causing people to feel angry. However, experiencing anger is not limited to the work context. That is, because work serves an important function in individuals' lives, creating a sense of purpose, belonging and identity (Walsh \& Gordon, 2008), the impact of work-induced stressors is not confined within the organizational boundaries. Furthermore, the formal nature of the work environment and the importance of preserving one's job may impede employees' ability to express anger in the work context, which in turn may result in a spillover of this anger to their private lives. In fact, scholars in the broader field of organizational behavior have acknowledged the possibility of a spillover effect of individuals' experiences from one life domain to another. In that regard, negative work-to-home spillover occurs when behaviors, stress and emotions from work negatively affect someone's private life (Edwards \& Rothbard, 2000; Grzywacz \& Marks, 2000).

The negative work-to-home spillover has already received support for a range of work-related experiences, such as general negative affect (Sonnentag \& Binnewies, 2013) and exhaustion (Grotto \& Lyness, 2010). Moreover, a few studies have demonstrated a link between the experience of daily work hassles and anger experienced at home; one study found that women experiencing sex-based harassment at work displayed more feelings of anger at home (Dionisi \& Barling, 2015), while another study found that employees reported greater 
marital anger at home following negative work experiences (Story \& Repetti, 2006). We want to replicate this effect by examining whether the experience of daily work stressors is positively associated with anger experienced at home.

Hypothesis 1: Employees' experience of daily work stressors will be positively associated with their experience of anger upon arrival home.

\section{Anger and Antisocial Online Behavior}

The theory of displaced aggression suggests that aggression is not always directed towards the original instigator of negative behavior but can also be directed toward innocent third parties (Dollard et al., 1939). This process of displaced aggression is especially prominent when the provoking person is unavailable (e.g., this person is not present anymore), the instigating factor is intangible (e.g., work environment) and/or when retaliating against the original instigator is risky (e.g., the instigator is your supervisor) (Miller, 1941). In such situations, individuals are inclined to control their anger and redirect it towards a more available and less powerful target. Furthermore, a triggering stimulus (e.g., a barking dog) that follows this initial provocation (e.g., work stressors) will make displaced aggression (e.g., kicking the dog) even more likely to occur (Dollard et al., 1939; Miller et al., 2003). Finally, the displaced aggression will go beyond what is expected following the tit-for-tat rule of exchange (Dollard et al., 1939). In support, a meta-analytical study of experimental literature confirmed the robustness of the displaced aggression effect (Marcus-Newhall et al., 2000).

Upon arrival home, employees are unable to express their stressor-evoked anger towards the initial source of this affect (i.e., work). It is therefore plausible that people may find a different way to vent their anger. In that regard, the online environment may lend itself well for the expression of displaced anger. According to Postmes et al. (1998), the anonymity and lack of social cues in online communication makes is easier for people to engage in 
negative behavior, as they are less self-aware and are detached from the human consequences of their action. This phenomenon of deindividuation in online communication is widely studied and has gained a lot of support (Dooley et al., 2009; Spears et al., 2002). According to Ho and McLeod (2008), the reduced social presence of others combined with one's own sense of anonymity makes people less inhibited to express how they truly feel online. Additionally, people dissociate their online persona from their offline selves, making them less concerned with what others think about them (the so-called online disinhibition effect; Suler, 2004). Because of this, people tend to display behaviors online that they would otherwise never engage in (Suler, 2004). Finally, less shared standards regarding appropriate behavior also contribute to people misbehaving online (Kiesler et al., 1984). All these factors make the online environment particularly suitable for an uninhibited expression of otherwise suppressed emotions.

In support, in their review of studies that investigated how emotions are expressed online, Derks et al. (2008) concluded that people express their intense negative emotions more overtly online as opposed to face-to-face. Studies have also found that people often turn to the internet following negative experiences, either for distraction and stress relief (Lavoie \& Pychyl, 2001) or to vent their negative emotions on social network sites (Wendorf \& Yang, 2015). Furthermore, evidence shows that negative emotions increase the odds of negative online behavior by $89 \%$ (Cheng et al., 2017). Finally, anger in specific has been linked to AOB (Ak et al., 2015). Consequently, we argue that because of the deindividuation and the disinhibition that make people behave more uninhibited online, the online environment will consist of many triggering stimuli (e.g., mean comments, annoying posts, messages overload). Such triggering stimuli will increase the chance of displaced aggression. Furthermore, the deindividuation and the disinhibition effect will also make the employee more likely to act out 
their aggressive impulse. Thus, the online environment will simultaneously act as a trigger of and a means for aggressive behavior.

We also argue that anger experienced at home will mediate the effect of daily work stressors on AOB enacted throughout the evening. Several mechanisms may account for this work-family link. For instance, individuals may simply transfer certain behaviors from the work to the family context. In other occasions, individuals may respond to dissatisfaction in one domain by pursuing tangible or intangible rewards in another. Also, emotions evoked in one domain may influence emotions and performance in the other domain (Edwards \& Rothbard, 2000). In support, it has been shown that individuals bring their negative affect back home from work (Doby \& Caplan, 1995). Further, evidence exists that people's emotional states at the end of their working day can be reflected in their subsequent behavior at home (Crouter et al., 1989). Finally, the argument that anger will mediate the relationship between stressors and AOB is in line with propositions of Vranjes et al. (2017): work stressors are the contextual events that lead to AOB trough the experience of anger because anger is an active negative emotion that mobilizes energy for confrontation (Moons et al., 2010) and fuels aggressive behavior (Barclay et al., 2005). It is important to note that we do not expect a direct effect of work stressors on AOB. People react differently to the experience of work stressors. While some may express their frustration overtly (Berkowitz, 1988), others may withdraw themselves, keeping their negative feelings to themselves (Dijkstra et al., 2009). Furthermore, work stressors have been associated with a range of negative emotions, including anxiety, sadness, and depressive mood (Ohly \& Schmitt, 2013). These emotions have very different implications for people's behavior. While anger mobilizes people for action and causes people to engage in risky behaviors (Lazarus, 1991; Lerner \& Keltner, 2001), emotions such as anxiety and sadness are related to risk aversion and internalizing tendencies (Chorpita \& Barlow, 1998; Tiedens \& Linton, 2001). We therefore expect work 
stressors to only lead to AOB in employees through anger, which would drive them to behave in an antisocial way.

Hypothesis 2: Employees' anger upon arrival home will be positively associated with their engagement in antisocial online behaviors throughout the evening.

Hypothesis 3: Employees' anger after work will mediate the effect of daily work stressors on online antisocial behavior.

\section{Crossover of Anger and Antisocial Online Behavior}

As suggested previously, following a stressful workday, people may come home angry and displace that anger online. However, this work-related anger can also affect people closest to them. Regarding the interrelatedness between the work and family context, Bakker et al. (2009) proposed that work-related experiences spill over to the home domain and cross over to significant others. Crossover refers to "bi-directional transmission of positive and negative emotions, mood, and dispositions between intimately connected individuals such as spouses or organizational team members" (Westman et al., 2009, p.589). Couples spend considerable time together, making direct crossover between their experiences possible (Westman \& Vinokur, 1998). Consequently, a lot of recent research has focused on partner dyads and how partners may influence each other (e.g., Demerouti, 2012; Ferguson et al., 2015; Liu, et al., 2016). Studies have widely confirmed the existence of crossover of negative emotions between spouses (Westman, 2001). Furthermore, according to the leading researchers on crossover effects, these processes are no different for men and women (Westman \& Etzion, 1995).

There are several ways in which emotions may cross over to significant others. Authors propose that emotional contagion is an important mechanism for crossover in couples (Bakker \& Schaufeli, 2000). Couples communicate with each other about their daily events 
and experiences, especially when those experiences are negative. This act of communication can help employees make sense of their day, vent, or gain sympathy. However, because emotions are often contagious (Barsade, 2002), people who express their emotions may end up transferring those emotions to their partner (Bakker \& Shaufeli, 2000). Furthermore, emotions can also cross over from one partner to another through empathic reactions (Westman \& Vinokur, 1998). Empathy refers to a process of placing oneself psychologically in someone else's shoes and being affected by that other person's affective state (Lazarus, 1991; Starcevic \& Piontek, 1997). When people express their emotions, this is likely to evoke an empathetic reaction in their partner and make them experience these emotions as well (Westman et al., 2009). Empirical research supports the notion of emotional crossover in couples (e.g. Bakker et al., 2009; Rodríguez-Muñoz et al., 2014; Shimazu et al., 2011). Consequently, it is likely the partner of an angry employee will experience anger as well.

Furthermore, the crossover is not necessarily limited to the experienced emotions. According to Larson and Almeida (1999), emotional transmission of events or emotions in one family member can predict both emotions and behaviors in another family member. In that regard, Westman (2001) describes the notion of indirect crossover, which relates to an instance where experiences of one individual affect more distal experiences of their partner through mediating factors. In line with this, once emotions have been transmitted from one partner to another, they can subsequently fuel behavior in the partner. Specifically, in our study we argue that the crossed-over anger may act as a fuel for AOB in the partner of the employee experiencing work stressors. Namely, as emotions drive behavior, and anger predicts retaliatory behavior (Miron et al., 2008), crossed-over anger will drive the partner to behave aggressively as well. However, as this crossed-over anger is a result of contagion and empathetic processes, the person experiencing crossed-over anger will not have an obvious culprit. This unavailability of a culprit will therefore increase the likelihood of them engaging 
in displaced aggression (Miller, 1941), while the disinhibition and deindividuation processes will make the online environment a suitable context for the expression of such aggression. Thus, integrating insights from the crossover literature with theory on displaced aggression and disinhibition and deindividuation processes, we expect that the crossed-over anger stemming from an employees' experience of work stressors will drive AOB behavior in their partner. The model depicted in Figure 1 summarizes all the proposed relationships.

Hypothesis 4: Employees' anger after work will be positively associated with their partner's anger after work.

Hypothesis 5: The crossover of anger between partners will mediate the effect of an employee's daily work stressors to their partner's AOB throughout the evening.

\section{-----INSERT FIGURE 1 ABOUT HERE-----}

\section{METHOD}

\section{Procedure}

In this study, we applied a daily diary approach because this method allows us to capture events and experiences as they unfold over time in their natural context (Bolger et al., 2003) and is hence well suited to examine daily work stressors, emotions and antisocial online behavior. Another advantage of the diary design is that it limits the likelihood of retrospection by reducing the time span between the survey and the event or experience of interest (Bolger et al., 2003). In a time-based design, dual-earner couples reported on their experience of stressors at work, emotions, media use, and online behavior. Participants were assessed twice a day during five consecutive working days (Monday-Friday). Participants completed a diary prompt immediately after work (T1) and another diary prompt at the end of the day (T2). At $\mathrm{T} 1$, the diary assessed their experience of work stressors during the workday, together with 
their experienced emotions after work. At T2, we once more measured participants' anger, their time spent on social media after work, and their AOB throughout the evening. AOB was only assessed at $\mathrm{T} 2$ because we were only interested in AOB in the private context.

Participants completed the diaries electronically using their smartphone or their computer. Before the start of the study, they were contacted by telephone and thoroughly informed by the researchers about the whole process (i.e., the duration of the study, how to access the diaries and when to complete them). They also received a trial link to inspect the compatibility of the questionnaire with their device. During the data collection, participants received daily reminders via text message or email to complete the diaries at a time point indicated by themselves as most appropriate given their weekly work schedule. Finally, in addition to the diary questions, participants also completed a pre-measurement containing general demographic information, such as age, gender, and work background. Anonymity of all individual responses was guaranteed. The study was approved by the Ethics Committee for the Social Sciences and Humanities of the [Anonymized].

\section{Participants}

The sample consisted of 95 dual-earner couples who filled out the diary during five consecutive working days, two times a day, providing 950 data points. The participants were on average 44 years old (male average $=45$, female average $=43$ ). To be eligible for the study, both members of the couple had to be employed at least part-time. $95 \%$ of males and $45 \%$ of females worked full-time, while the remainder worked part-time, which is in line with the general Belgian working population (Statbel, 2016). Initially, 36 couples were recruited by launching an appeal in different organizations, universities, and on social media. To reach a higher number of participants, additional couples were recruited via a market research agency. Participants received a monetary incentive of $€ 100$ per couple, if both partners completed at 
least $80 \%$ of the diaries. Most participants completed all the diaries at both times points. A few missing values could be attributed to technical issues (i.e., not receiving a reminder to complete the diary in time). Further, not all diary entries were completed at the requested time points. For T1 (right after work), diaries that were completed less than one hour before T2 (at the end of the day) were omitted. For T2, diaries that were completed the following morning were omitted. This resulted in the following missing data rates: $34(8 \%)$ of the females', and $20(4 \%)$ of the males' entries at T1; and $34(8 \%)$ of the females', and $33(7 \%)$ of the males' entries at T2. On a daily basis, this resulted in an average cluster size of 90 couples.

\section{Measures}

Work stressors (T1). Work-related stressful events during the day were assessed with seven items from the Daily Hassles and Uplifts Scale (DeLongis et al., 1982). For each item, participants had to indicate whether or not $(0=$ no; $1=$ yes $)$ they had experienced the work related stressor ("You had an unpleasant experience with a colleague", "You had an unpleasant experience with a client", "You had an unpleasant experience with your supervisor", "You experienced a lot of work pressure", "You struggled with the content of our work", "You struggled to meet the deadlines", "You experienced insecurity regarding your job") that day. For each day, a stress index per person was created by calculating the sum of the items. As this is a formative measure, internal reliability is not useful to assess (Coltman et al., 2008).

Anger (T1 and T2). Participants were asked to rate their current level of anger on a Likert-type scale from Not at all (1) to Very strong (5). According to Ohly et al. (2010), singleitem measures can be useful in diary studies, as they reduce response fatigue. Furthermore, Elo et al. (2003) showed that single-item indicators of stress symptoms, including emotions, display good content, criterion, and construct validity. Finally, following the recommendations by 
Fisher et al. (2012), who show that single-item measures can reliably measure different constructs when properly selected, we selected the item from the State-Trait Anger Expression Inventory (Spielberger, 1999), with the highest loading on the state anger factor.

Antisocial online behavior (AOB; T2). Participants' daily antisocial online behavior was assessed with five items from the European Cyberbullying Intervention Project Questionnaire (Brighi et al., 2012; Del Rey et al., 2015; Schultze-Krumbholz et al., 2015) which we modified for diary use ("Posting a negative comment to a message, image or video", "Putting shameful images or videos of others online or sharing these with others", "Saying mean things to someone or about someone online", "Gossiping about someone online" and "Ignoring or excluding someone online"). On a Likert-type scale ranging from Not at all (1) to Very much (5), participants were asked to rate how often they had committed these behaviors after work hours. Because of the highly skewed nature of the responses on the $\mathrm{AOB}$ items (skewness $=7.4, \mathrm{SE}=0.16$ ), we treated $\mathrm{AOB}$ as a categorical variable - no $\mathrm{AOB}$ committed (0) or at least one type of AOB committed (1) throughout the evening.

\section{Control variables}

Gender. We controlled for gender because scholars have demonstrated that anonymity offered by online communication can lead to more pronounced gender differences online, leading to more gender-stereotypic behavior (Postmes \& Spears, 2002). In other words, the gender difference in predisposition towards aggressive behavior could be further exaggerated online. In line with this, men are found to engage more in hostile online communication then women (Alonzo \& Aiken, 2004).

Time spent on digital media. Because previous evidence demonstrates that time spent online is related to AOB enactment (Lee \& Shin, 2017; Mishna et al., 2012), we also controlled for time people spent on digital media after work. Participants were asked to rate 
their time spent on digital media (e.g., smartphone, computer, tablet) for social use during the period between work and sleep on a 5-point Likert-type scale from Not at all to A lot (2 hours or more).

\section{Analyses}

Due to the nested nature of the daily diary data (i.e., repeated measures nested within individuals), we conducted multilevel analyses in Mplus 7.4 (Muthen \& Muthen, 2015). To test the appropriateness of using a multilevel approach, intraclass coefficients (ICC) - which indicate the relative amount of between-person and within-person variance - were estimated based on an unconditional random coefficient model. They revealed that anger T1 and AOB respectively displayed $81 \%$ and $68 \%$ of within-person variation for men and $71 \%$ and $80 \%$ for women. As expected, most variance was located at the within-person level. However, there was also a considerable portion of between-person variance (which indicated more stable, trait-like differences in propensity to experience anger and engage in antisocial online behavior). In our analyses, we therefore estimate both the within- and the between-person effects, to test whether the proposed relationships operate on the within-person level as hypothesized. As we estimated effects on both levels, we did not center the key study variables - in such cases Mplus creates two separate variance components, one on the withinand the other on the between-person level (Muthen \& Muthen, 2015). We only used observation on the days that participants indicated that they had worked to ensure that work related anger was the driver behind people's AOB in the evening. Finally, we used the Bayesian estimator with a noninformative prior, which does not assume normality and allows for a more accurate and reliable estimations of mediation effects for complex models with small sample sizes (Enders et al., 2013; Yuan \& MacKinnon, 2009).

\section{RESULTS}


Table 1 shows the means, standard deviations and intercorrelations of the study variables for men and women separately, on the within- and the between-person level. Insert Table 1 about here

\section{The Spillover Hypotheses}

As presented in Table 2 and 3, for both men (estimate $=0.35, p<0.01)$ and women (estimate $=0.32, p<0.01$, we found a positive association between their daily stressors and daily anger after work, confirming Hypothesis 1. Furthermore, for men, we found a positive association between anger $\mathrm{T} 1$ and $\mathrm{AOB} \mathrm{T} 2(\mathrm{OR}=1.84, p<0.05)$ when controlling for time spent online and anger T2. Finally, for men, anger T1 fully mediated the effect of daily work stressors $\mathrm{T} 1$ on daily AOM T2 $(\mathrm{OR}=1.15,95 \% \mathrm{CI}$ of the $\mathrm{OR}=[1.02,1.33])$. No significant effect of anger T1 on AOB T2 was found for women, and there was also no mediating effect of anger on the relationship between work stressors T1 and AOB T2. Thus, Hypothesis 2 and 3 were confirmed for men, but not for women. Finally, for men, between-person effects were not significant, indicating that within-person fluctuations in stressors and emotions, as opposed to differences between people in experiencing these variables were of importance in predicting AOB. For women, only a significant between-person effect of stressors on anger was found, indicating that women who on average experienced more stressors also reported on average more anger after work.

\section{The Crossover Hypotheses}

Regarding the crossover hypotheses (Table 2), we found no crossover effects of women's stressors and anger on men's anger T1 and AOB T2. We also did not find a significant crossover of men's stressors and anger on women's anger. Thus, Hypothesis 4 was not confirmed. However, we did find a significant effect of men's anger T1 on women's AOB $\mathrm{T} 2(\mathrm{OR}=1.86, p<0.05)$. We did not find a significant mediating effect of crossed-over anger 
from men to women on women's AOB T2, however we did find a significant effect of men's stressors T1 on women's AOB T2 through men's anger T1 $(\mathrm{OR}=1.15, p<.05, \mathrm{CI}$ of the OR $=[1.02,1.33])$, thus partially confirming Hypothesis 5 . No between-person effects regarding the hypothesized relationships were found.

Insert Table 2 about here

Insert Table 3 about here

\section{DISCUSSION}

Modern technology provides us with many opportunities, including the opportunity to create new connections and keep track of the old ones. Many people engage with digital media in their spare time as a means of finding a distraction for their daily routine (Vaterlaus et al., 2015). Furthermore, previous research suggests that engaging with online media could also play an important role in individuals' emotional life. That is, research shows that individuals often engage in emotional sharing online as a way of dealing with their daily emotions (Choi \& Toma, 2014). Consequently, in this study, we aimed to investigate whether the digital environment can provide a convenient context for expressing displaced aggression following the experience of daily work stressors. Our results indicate that men who experience work stressors during the day feel angry after work and engage in AOB throughout the evening. This is an important finding because it confirms that men may engage with online media to vent their work-induced anger. Furthermore, we found that women who experienced work stressors during the day also felt angry after work, but their anger was not translated in AOB throughout the evening. However, we did find a crossover of their partner's daily work stressors on their own AOB throughout the evening. In other words, women's AOB after work seemed to be impacted by their partner, rather than by their work. 
This study has several important implications for theory and research. First, this study contributes to the AOB literature by investigating antecedents of aggressive online behavior in working adults. AOB has been widely investigated in the adolescent population, with studies investigating its prevalence (Selkie et al., 2016), consequences (Hinduja \& Patchin, 2007), and potential causes (Heirman \& Walrave, 2012). Yet, research on adult AOB remains in its infancy (Vranjes et al., 2017) and we still lack understanding of the factors that may cause working adults to engage in this type of aggressive behavior. This study suggests that workplace stressors and emotions may predict AOB in working individuals. As such, it confirms the work environment hypothesis (Einarsen et al., 1994; Leymann, 1996), according to which the psychosocial work environment is an important precursor of bullying behavior, and extends it to the online environment. Additionally, this study highlights the need for more studies using experience sampling for capturing the relationship between emotions and aggressive behavior in employees. Studies using cross-sectional or longitudinal designs with long time lags only allow conclusions regarding between-person differences in tendencies to experience certain emotions and engage in aggressive behavior. In our study we show that it may be more relevant to capture people's immediate responses to experiencing certain emotions. This approach also more closely aligns with the definition of emotions as dynamic and short-lived (Zautra et al., 2005).

Second, it illustrates that work stressors can affect individuals beyond their work context by changing their behavior patterns at home. This is an important finding because studies investigating spillover of work stress to the home environment have often focused on employees' affect, attitudes, and relationship outcomes at home (e.g., Rodríguez-Muñoz et al., 2014; Sanz-Vergel et al., 2015; Wunder \& Heineck, 2013), while less attention has been given to how work stress could influence concrete behaviors in the private context. These findings suggest that the current stress literature could profit from a more extensive 
consideration of how work can affect employees' after work leisure activities, as people may not always engage in such activities in a constructive way. Also, this study shows that the online environment may lend itself perfectly to the enactment of displaced aggression. This can be attributed to certain characteristics of the online environment—such as the reduced social presence, the perceived anonymity and the lack of social norms (Dooley et al., 2009) which allow for a more uninhibited expression of displaced anger. This highlights an inherently problematic nature of this communication medium and calls for more research regarding the way the online environment can be designed in a way that reduces online aggression.

Finally, the results of this study also suggest important gender differences in the relationship between work stressors, anger, and antisocial online behavior. Namely, we find that both men and women engage in AOB after work, but that for men, AOB is the result of displaced aggression stemming from their own work stressors, while for women, AOB is the result of displaced aggression stemming from their partner's work stressors. Apparently, the source of stress is important in the prediction of daily antisocial online behavior in working adults. These findings are in accordance with Pleck's (1979) sensitization theory. According to Pleck $(1979,1985)$, men's self-esteem and identity are traditionally more linked to their performance of the work role, while women's self-concept is traditionally more strongly associated with their performance of the parenting and spouse roles. According to this theory, even when men and women are equally involved in the work role, societal pressure makes men more sensitive to work-related problems, because such problems can hinder their work role success and thus their status in the eyes of others. The same applies to women regarding family-related problems. Other authors (e.g., Voydanoff, 2002) and empirical studies (e.g., Simon, 1995) also lend support for this idea. Furthermore, leading researchers on crossover effects also suggest that women may be more strongly affected by their partner's stress and 
strain than vice versa (Westman, 2001, 2009). This is because women are more socialized to be sensitive to others' emotions and develop dispositional empathy (Larson \& Almeida, 1999; Westman 2001). In our study, it is possible that work stressors had a stronger negative influence on men's identity and self-esteem than on women's, creating a stronger incentive to displace the work-related anger online. In contrast, given the importance women place on their family and personal relationships, women could have been more strongly affected by stressors coming from their partner, resulting in more partner-induced displaced aggression online.

\section{Future Research Directions}

In this study, which investigated antecedents of AOB on the daily basis, we focused on a particular predicting process regarding work stressors and emotions. An interesting future avenue would be to look at whether certain types of work stressors have a stronger link to displaced AOB than others. Having control over a stressor can seriously diminish its negative effect on individuals, while a lack of control over stressors is related to impaired functioning (Folkman \& Lazarus, 1980). It is possible that less controllable work stressors (e.g., job insecurity) would stimulate more displaced aggression than more controllable stressors (e.g. workload). In addition, given the above reasoning regarding gender differences in experienced stress, it may be possible that work stressors that are more interpersonal in nature would result in more displaced aggression in women. Future studies could therefore investigate whether the type of experienced work stressor matters for observing displaced AOB.

Another interesting future avenue would be to further investigate how men and women differ in their online expression of anger. As people regularly use updates on their social networking sites for emotional disclosure (Manago, et al., 2012), it could be that women experiencing anger after work would rather engage in online communication in order to 
disclose their emotions and seek support, rather than to vent their anger. In that regard, evidence shows that Internet use can decrease loneliness and depression, while increasing social support and self-esteem (Shaw \& Gant, 2002). Furthermore, it would also be interesting to explore boundary conditions for women engaging in AOB in the private setting following work-related anger. In that regard, studies find that men engage in impulsive behavior of flaming (extreme negativity, insulting, swearing, offending or hostile comments online, often directed towards strangers) more than women (Alonzo \& Aiken, 2004). On the contrary, no gender effects are found in more deliberate forms of AOB, such as cyberbullying (Kowalski et al., 2014). It could therefore be that while men engage more in impulsive venting of anger online, there are no differences in gender regarding the more deliberate forms of online aggression. Additionally, according to the theory of triggered displaced aggression (Dollard et al., 1939), a triggering event is more likely to result in people engaging in displaced aggression. However, we did not assess such triggers in the online environment in this study. Previous research has shown that aggression is more likely to occur in anonymous online platforms and when other people display uncivil behavior themselves (e.g., Rösner \& Krämer, 2016). It would therefore be interesting to further explore different types of online triggers that can make displaced online aggression following work stress more likely.

Finally, it would be interesting to investigate whether displaced aggression is more likely to occur in certain online contexts than in others. Anonymity is associated with more online aggression (Moore et al., 2012). Thus, people may be more inclined to display displaced aggression when their identity is not disclosed (e.g., anonymous comments on public websites), compared to when their identity is public (e.g., own social media posts). Furthermore, it would also be interesting to explore individual boundary conditions for employees engaging in $\mathrm{AOB}$ in the private setting following work-related anger. In that regard, it is possible that people with good emotion regulation skills (Buruck et al., 2016) or 
with a strong social support network (Xie \& Xie, 2019), who have a more adaptive way of dealing with their emotions, would be less inclined to express their negative emotions online.

\section{Limitations}

The results of this study should be evaluated in the light of its strengths and weaknesses. First, in testing the spillover hypotheses, we measured certain variables at the same point in time (i.e., stressors and anger at T1). As a consequence, we cannot establish the true directionality of our effects. However, the predictive power of stressors on anger has been well established in different studies and contexts (e.g., Ayoko et al., 2012). Second, since we did not measure who the target of AOB after work was, we cannot exclude the possibility that $\mathrm{AOB}$ was directed towards a colleague or a supervisor. However, given that we measured both tangible (e.g., "You had an unpleasant experience with a colleague/a client/your supervisor"), and intangible (e.g., "You experienced a lot of work pressure") sources of work stress, there is no reason to assume the AOB would have been directed towards a particular person. Finally, our dependent variable of AOB had low prevalence rates, resulting in it having a highly skewed distribution. To deal with this issue, we treated AOB as a categorical variable. However, despite the low prevalence of AOB in working individuals, we still found significant results, which adds to our confidence in our findings. Third, although one of the study prerequisites was that couples participating had to be living together during the course of the study, we did not measure the exact time couples spent together in the evening. In other words, the absence of certain effects, especially with regards to the crossover hypothesis, could potentially be explained by limited contact between couples in the evening. For instance, in this study, we did not find a significant crossover of anger between members of a couple. This is surprising, as such emotional crossover has been widely studied and confirmed by empirical research (Amstad \& Semmer, 2011; Sanz-Vergel et al., 2012). It is therefore possible that controlling for time spent together could have resulted in more 
significant crossover effects. Furthermore, since we asked participants to report on their anger right after work, it is possible that the couples did not yet spend sufficient time together for a crossover to occur. This would explain why there was a significant direct crossover of men's anger after work on women's AOB throughout the evening. An additional measurement point (e.g., during the evening) would have possibly enabled us to observe a significant crossover effect of anger and a mediating effect of crossed-over ager on women's AOB.

\section{Practical Implications}

This study has important practical implications because it underlines the impact of work on people's daily lives, beyond organizational boundaries. Specifically, we showed that employees might engage in AOB following the experience of work-related frustration and that work stressors may affect their partners as well. These results suggest that organizations have a societal responsibility in creating healthy work environments; poor work environments might not only impact functioning and well-being of employees but may also negatively affect the well-being of other people outside the organizational context (i.e., employees' partners and people exposed to negative online behavior). We therefore urge organizations to permanently invest in promoting a healthy work environment and increasing employee wellbeing (for a review of interventions and their effectiveness, see Richardson et al., 2008). This could be done by reducing the requirements for employees to remain connected and available online after work hours, especially since extended availability has been found to reduce employees' well-being (Dettmers et al., 2016).

Furthermore, this study shows that the online environments lends itself for the expression of displaced aggression. In the further efforts to better understand processes leading to phenomena such as online aggression and cyberbullying, it is important to take into account these unique characteristics of the online environment and think about ways in which 
they can be modified in order to create a more safe and civil environment for the online users. In that regard, some researchers propose that creating clear guidelines regarding appropriate behavior and reducing anonymity can aid in creating more civil online environments (e.g., Zimmerman \& Ybarra, 2016). Also, as employees may engage in antisocial online behaviors both during and after work hours, it is important for organizations to educate people about the effects that the online environment may have on their behavior. Organizations should develop workshops aimed at educating people about the 'netiquette' (Brown, 2014), including teaching employees the proper way of communicating online (e.g., how to avoid ambiguous communication) and when to use which medium for communication (e.g., e-mail, telephone or instant messaging). Organizations can also organize workshops aimed at increasing employees' digital literacy and more specific, their understanding of the digital space, by explaining the unique nature of this environment and the effect it can have in shaping our behavior. 


\section{REFERENCES}

Ak, S., Ozdemir, Y., \& Kuzucu, Y. (2015). Cybervictimization and cyberbullying: The mediating role of anger, don't anger me! Computers in Human Behavior, 49, 437-443.

Alonzo, M., \& Aiken, M. (2004). Flaming in electronic communication. Decision Support Systems, 36(3), 205-213.

Amstad, F. T., \& Semmer, N. K. (2011). Spillover and crossover of work-and family-related negative emotions in couples. Psychology of Everyday Activity, 4(1), 43-55.

Ayoko, O. B., Konrad, A. M., \& Boyle, M. V. (2012). Online work: Managing conflict and emotions for performance in virtual teams. European Management Journal, 30(2), 156174.

Bakker, A. B., Demerouti, E., \& Burke, R. (2009). Workaholism and relationship quality: A spillover-crossover perspective. Journal of Occupational Health Psychology, 14(1), 23.

Bakker, A. B., \& Schaufeli, W. B. (2000). Burnout Contagion Processes Among Teachers 1. Journal of Applied Social Psychology, 30(11), 2289-2308.

Bakker, A., Shimazu, A., Demerouti, E., Shimada, K., \& Kawakami, N. (2013). Work engagement versus workaholism: A test of the spillover-crossover model. Journal of Managerial Psychology, 29(1), 63-80.

Bakker, A. B., Westman, M., \& van Emmerik, H. I. J. (2009). Advancements in crossover theory. Journal of Managerial Psychology, 24(3), 206-219.

Barclay, L. J., Skarlicki, D. P., \& Pugh, S. D. (2005). Exploring the role of emotions in injustice perceptions and retaliation. Journal of Applied Psychology, 90(4), 629-643.

Barsade, S. G. (2002). The ripple effect: Emotional contagion and its influence on group behavior. Administrative Science Quarterly, 47(4), 644-675.

Berkowitz, L. (1988). Frustrations, appraisals, and aversively stimulated aggression. Aggressive Behavior, 14(1), 3-11.

Bensimon, H. F. (1997). What to do about anger in the workplace?. Training \& Development, 51(9), 28-33.

Bernstein, M. S., Monroy-Hernández, A., Harry, D., André, P., Panovich, K., \& Vargas, G.(2011). 4chan and /b/: An analysis of anonymity and ephemerality in a large online community. In Proceedings of AAAI Conference on Weblogs and Social Media (ICWSM) (pp. 50-57). Menlo Park, CA: AAAI Press.

Bharadwaj, A. S. (2000). A resource-based perspective on information technology capability and firm performance: an empirical investigation. MIS Quarterly, 24(1), 169-196.

Bliese, P. D., Edwards, J. R., \& Sonnentag, S. (2017). Stress and well-being at work: A century of empirical trends reflecting theoretical and societal influences. Journal of Applied Psychology, 102(3), 389-402.

Bolger, N., Davis, A., \& Rafaeli, E. (2003). Diary methods: Capturing life as it is lived. Annual Review of Psychology, 54, 579-616. 
Bolino, M. C. (1999). Citizenship and impression management: Good soldiers or good actors? Academy of Management Review, 24(1), 82-98.

Brighi, A., Ortega, R., Pyzalski, J., Scheithauer, H., Smith, P. K., Tsormpatzoudis, H., \& Al., E. (2012). European Cyberbullying Intervention Project Questionnaire - ECIPQ. Retrieved from bullyingandcyber.net

Brown, S. A. (2014). Conceptualizing digital literacies and digital ethics for sustainability education. International Journal of Sustainability in Higher Education, 15(3), 280-290.

Buruck, G., Dörfel, D., Kugler, J., \& Brom, S. S. (2016). Enhancing well-being at work: The role of emotion regulation skills as personal resources. Journal of Occupational Health Psychology, 21(4), 480-493.

Catalano, R. E, \& Hawkins, J.D. (1996). The social development model: A theory of antisocial behavior. In J. D. Hawkins (Ed.), Delinquency and crime: Current theories (pp. 149-197). New York: Cambridge University Press.

Cheng, J., Bernstein, M., Danescu-Niculescu-Mizil, C., \& Leskovec, J. (2017). Anyone Can Become a Troll: Causes of Trolling Behavior in Online Discussions. In CSCW'17: Proceedings of the 2017 ACM Conference on Computer Supported Cooperative Work and Social Computing, 1217-1230.

Chinn, M. D., \& Fairlie, R. W. (2010). ICT use in the developing world: an analysis of differences in computer and internet penetration. Review of International Economics, 18(1), 153-167.

Choi, M., \& Toma, C. L. (2014). Social sharing through interpersonal media: Patterns and effects on emotional well-being. Computers in Human Behavior, 36, 530-541.

Coltman, T., Devinney, T. M., Midgley, D. F., \& Venaik, S. (2008). Formative versus reflective measurement models: Two applications of formative measurement. Journal of Business Research, 61(12), 1250-1262.

Coyne, I., Farley, S., Axtell, C., Sprigg, C., Best, L., \& Kwok, O. (2017). Understanding the relationship between experiencing workplace cyberbullying, employee mental strain and job satisfaction: a dysempowerment approach. The International Journal of Human Resource Management, 28(7), 945-972.

Crouter, A. C., Perry-Jenkins, M., Huston, T. L., \& Crawford, D. W. (1989). The influence of work-induced psychological states on behavior at home. Basic and Applied Social Psychology, 10(3), 273-292.

D'Cruz, P., \& Noronha, E. (2014). The interface between technology and customer cyberbullying: Evidence from India. Information and Organization, 24(3), 176-193.

DeLongis, A., Coyne, J. C., Dakof, G., Folkman, S., \& Lazarus, R. S. (1982). Relationship of daily hassles, uplifts, and major life events to health status. Health Psychology, 1(2), 119-136.

Del Rey, R., Casas, J. A., Ortega-Ruiz, R., Schultze-Krumbholz, A., Scheithauer, H., Smith, P., ... Plichta, P. (2015). Structural validation and cross-cultural robustness of the European Cyberbullying Intervention Project Questionnaire. Computers in Human Behavior, 50, 141-147. 
Demerouti, E. (2012). The spillover and crossover of resources among partners: The role of work-self and family-self facilitation. Journal of Occupational Health Psychology, 17(2), 184-195.

Derks, D., Fischer, A. H., \& Bos, A. E. R. R. (2008). The role of emotion in computermediated communication: A review. Computers in Human Behavior, 24(3), 766-785.

Dettmers, J., Vahle-Hinz, T., Bamberg, E., Friedrich, N., \& Keller, M. (2016). Extended work availability and its relation with start-of-day mood and cortisol. Journal of Occupational Health Psychology, 21(1), 105-118.

Dijkstra, M. T., De Dreu, C. K., Evers, A., \& van Dierendonck, D. (2009). Passive responses to interpersonal conflict at work amplify employee strain. European Journal of Work and Organizational Psychology, 18(4), 405-423.

Dionisi, A. M., \& Barling, J. (2015). Spillover and crossover of sex-based harassment from work to home: Supervisor gender harassment affects romantic relationship functioning via targets' anger. Journal of Organizational Behavior, 36(2), 196-215.

Dollard, J., Miller, N. E., Doob, L. W., Mowrer, O. H., \& Sears, R. R. (1939). Frustration and aggression. New haven, CT: Yale University Press.

Dooley, J. J., Pyżalski, J., \& Cross, D. (2009). Cyberbullying versus face-to-face bullying: A theoretical and conceptual review. Zeitschrift für Psychologie/Journal of Psychology, 217(4), 182-188.

Edwards, J. R., \& Rothbard, N. P. (2000). Mechanisms linking work and family: Clarifying the relationship between work and family constructs. Academy of Management Review, 25(1), 178-199.

Einarsen, S., Raknes, B. I., \& Matthiesen, S. B. (1994). Bullying and harassment at work and their relationships to work environment quality: An exploratory study. European Work and Organizational Psychology, 4(4), 381-401.

Elo, A., Leppa nen, A., \& Jahkola, A. (2003). Validity of a single-item measure of stress symptoms. Scandinavian Journal of Work Environment and Health, 29(6), 441-451.

Enders, C. K., Fairchild, A. J., \& MacKinnon, D. P. (2013). A Bayesian approach for estimating mediation effects with missing data. Multivariate Behavioral Research, 48(3), 340-369Fan, R., Zhao, J., Chen, Y., \& Xu, K. (2013). Anger is more influential than joy: Sentiment correlation in Weibo. Retrieved from http://arxiv.org/abs/1309.2402.

Farley, S., Coyne, I., Sprigg, C., Axtell, C., \& Subramanian, G. (2015). Exploring the impact of workplace cyberbullying on trainee doctors. Medical Education, 49(4), 436-443.

Ferguson, M., Carlson, D., \& Kacmar, K. M. (2015). Flexing work boundaries: The spillover and crossover of workplace support. Personnel Psychology, 68(3), 581-614.

Festinger, L., Pepitone, A., \& Newcomb, T. (1952). Some consequences of de-individuation in a group. The Journal of Abnormal and Social Psychology, 47(2), 382-389.

Fida, R., Paciello, M., Tramontano, C., Fontaine, R. G., Barbaranelli, C., \& Farnese, M. L. (2015). An integrative approach to understanding counterproductive work behavior: The roles of stressors, negative emotions, and moral disengagement. Journal of Business 
Ethics, 130(1), 131-144.

Fisher, G. G., Matthews, R. A., \& Gibbons, A. M. (2016). Developing and investigating the use of single-item measures in organizational research. Journal of Occupational Health Psychology, 21(1), 3-23.

Fitness, J. (2000). Anger in the workplace: An emotion script approach to anger episodes between workers and their superiors, coworkers and subordinates. Journal of Organizational Behavior, 21(2), 147-162.

Folkman, S., \& Lazarus, R. S. (1980). An analysis of coping in a middle-aged community sample. Journal of Health and Social Behavior, 21, 219-239.

Forssell, R. (2016). Exploring cyberbullying and face-to-face bullying in working lifePrevalence, targets and expressions. Computers in Human Behavior, 58, 454-460.

Frijda, N. (1986). The Emotions: Studies in emotion and social interaction. New York: Cambridge University Press.

Gardner, D., O’Driscoll, M., Cooper-Thomas, H. D., Roche, M., Bentley, T., Catley, B., Teo, S. T. T., \& Trenberth, L. (2016). Predictors of workplace bullying and cyber-bullying in New Zealand. International Journal of Environmental Research and Public Health, 13(5), 448-462.

Gianakos, I. (2002). Issues of anger in the workplace: Do gender and gender role matter?. The Career Development Quarterly, 51(2), 155-171.

Glas $\varnothing$, L., Vie, T. L., Holmdal, G. R., \& Einarsen, S. (2010). An application of affective events theory to workplace bullying. European Psychologist, 16, 198-208.

Gross, J. J., \& Thompson, R. A. (2007). Emotion regulation: Conceptual foundations. In J. J. Gross (Ed.), Handbook of emotion regulation. New York: Guilford Press.

Grotto, A. R., \& Lyness, K. S. (2010). The costs of today's jobs: Job characteristics and organizational supports as antecedents of negative spillover. Journal of Vocational Behavior, 76(3), 395-405.

Grzywacz, J. G., \& Marks, N. F. (2000). Reconceptualizing the work-family interface: An ecological perspective on the correlates of positive and negative spillover between work and family. Journal of Occupational Health Psychology, 5(1), 111-126.

Heirman, W., \& Walrave, M. (2012). Predicting adolescent perpetration in cyberbullying: An application of the theory of planned behavior. Psicothema, 24(4), 614-620.

Hinduja, S., \& Patchin, J. W. (2007). Offline consequences of online victimization: School violence and delinquency. Journal of School Violence, 6(3), 89-112.

Ho, S. S., \& McLeod, D. M. (2008). Social-psychological influences on opinion expression in face-to-face and computer-mediated communication. Communication Research, 35(2), 190-207.

Hofmann, D. A., \& Gavin, M. B. (1998). Centering decisions in hierarchical linear models: Implications for research in organizations. Journal of Management, 24(5), 623-641.

Hoggan, B. L., \& Dollard, M. F. (2007). Effort-reward imbalance at work and driving anger 
in an Australian community sample: Is there a link between work stress and road rage?. Accident Analysis \& Prevention, 39(6), 1286-1295.

Hunton, J. E., Lippincott, B., \& Reck, J. L. (2003). Enterprise resource planning systems: comparing firm performance of adopters and nonadopters. International Journal of Accounting Information Systems, 4(3), 165-184.

Hurrell, J. J., Nelson, D. L., \& Simmons, B. L. (1998). Measuring job stressors and strains: Where have we been, where we are, and where we need to go. Journal of Occupational Health Psychology, 3(4), 368-389.

Kenny, D. A., \& Cook, W. (1999). Partner effects in relationship research: Conceptual issues, analytic difficulties, and illustrations. Personal Relationships, 6(4), 433-448.

Kiesler, S., Siegel, J., \& McGuire, T. W. (1984). Social psychological aspects of computermediated communication. American Psychologist, 39(10), 1123-1134.

Korunka, C, \& Hoonakker, P. (Eds.). (2014). The impact of ICT on quality of working life. Dordrecht: Springer.

Kowalski, R. M., Toth, A., \& Morgan, M. (2018). Bullying and cyberbullying in adulthood and the workplace. The Journal of Social Psychology, 158(1), 64-81.

Lapidot-Lefler, N., \& Barak, A. (2012). Effects of anonymity, invisibility, and lack of eyecontact on toxic online disinhibition. Computers in Human Behavior, 28(2), 434-443.

Larson, R. W., \& Almeida, D. M. (1999). Emotional transmission in the daily lives of families: A new paradigm for studying family process. Journal of Marriage and the Family, 5-20.

Lavoie, J. A. A., \& Pychyl, T. A. (2001). Cyberslacking and the procrastination superhighway: A web-based survey of online procrastination, attitudes, and emotion. Social Science Computer Review, 19(4), 431-444.

Lazarus, R. S. (1991). Emotion and adaptation. New York: Oxford University Press.

Lazarus, R. S., \& Folkman, S. (1984). Stress, appraisal, and coping. New York: Springer Publishing.

Lee, C., \& Shin, N. (2017). Prevalence of cyberbullying and predictors of cyberbullying perpetration among Korean adolescents. Computers in Human Behavior, 68, 352-358.

Leymann, H. (1996). The content and development of mobbing at work. European Journal of Work and Organizational Psychology, 5(2), 165-184.

Lim, V. K., \& Teo, T. S. (2009). Mind your E-manners: Impact of cyber incivility on employees' work attitude and behavior. Information \& Management, 46(8), 419-425.

Liu, H., Ngo, H. Y., \& Cheung, F. M. (2016). Work-family enrichment and marital satisfaction among Chinese couples: A crossover-spillover perspective. International Journal of Stress Management, 23(2), 209-231.

Marcus-Newhall, A., Pedersen, W. C., Carlson, M., \& Miller, N. (2000). Displaced aggression is alive and well: A meta-analytic review. Journal of Personality and Social Psychology, 78(4), 670-689. 
Mawritz, M. B., Folger, R., \& Latham, G. P. (2014). Supervisors' exceedingly difficult goals and abusive supervision: The mediating effects of hindrance stress, anger, and anxiety. Journal of Organizational Behavior, 35(3), 358-372.

Meier, L. L., \& Spector, P. E. (2013). Reciprocal effects of work stressors and counterproductive work behavior: A five-wave longitudinal study. Journal of Applied Psychology, 98, 529-539.

Miller, N. E. (1941). The frustration-aggression hypothesis. Psychological Review, 48(4), 337-342.

Miller, N., Pedersen, W. C., Earleywine, M., \& Pollock, V. E. (2003). A theoretical model of triggered displaced aggression. Personality and Social Psychology Review, 7(1), 75-97.

Miron, A. M., Brummett, B., Ruggles, B., \& Brehm, J. W. (2008). Deterring anger and angermotivated behaviors. Basic and Applied Social Psychology, 30(4), 326-338.

Mishna, F., Khoury-Kassabri, M., Gadalla, T., \& Daciuk, J. (2012). Risk factors for involvement in cyber bullying: Victims, bullies and bully-victims. Children and Youth Services Review, 34(1), 63-70.

Moons, W. G., Eisenberger, N. I., \& Taylor, S. E. (2010). Anger and fear responses to stress have different biological profiles. Brain, Behaviour, and Immunity, 24(2), 215-219.

Moore, M. J., Nakano, T., Enomoto, A., \& Suda, T. (2012). Anonymity and roles associated with aggressive posts in an online forum. Computers in Human Behavior, 28(3), 861867.

Morse, N. C., \& Weiss, R. S. (1955). The function and meaning of work and the job. American Sociological Review, 20(2), 191-198.

Mignonac, K., \& Herrbach, O. (2004). Linking work events, affective states, and attitudes: An empirical study of managers' emotions. Journal of Business and Psychology, 19(2), 221240.

Muhonen, T., Muhonen, T., Jönsson, S., Jönsson, S., Bäckström, M., \& Bäckström, M. (2017). Consequences of cyberbullying behaviour in working life: The mediating roles of social support and social organisational climate. International Journal of Workplace Health Management, 10(5), 376-390.

Muthén, L. K., \& Muthén, B. O. (2015). Mplus user's guide (7th ed.). Los Angeles, CA: Muthén \& Muthén.

Ohly, S., \& Schmitt, A. (2013). What makes us enthusiastic, angry, feeling at rest or worried? Development and validation of an affective work events taxonomy using concept mapping methodology. Journal of Business and Psychology, 30(1), 15-35.

Ohly, S., Sonnentag, S., Niessen, C., \& Zapf, D. (2010). Diary studies in organizational research: An introduction and some practical recommendations. Journal of Personnel Psychology, 9, 79-93.

Payne, R. L. (2001). Measuring emotions at work. In R. L. Payne \& C. L. Cooper (Eds.). Emotions at work. (pp. 107-133). Chichester, U.K.: Wiley \& Sons. 
Pfeffer, J., Zorbach, T., \& Carley, K. M. (2014). Understanding online firestorms: Negative word-of-mouth dynamics in social media networks. Journal of Marketing Communications, 20(1-2), 117-128.

Pleck, J. (1979). Work-family conflict: A national assessment. Paper presented at the annual meeting of the Society for the Study of Social Problems, Boston.

Pleck, J. (1985). Working wives/working husbands, Beverly Hills, CA: Sage.

Postmes, T., \& Spears, R. (2002). Behavior online: Does anonymous computer communication reduce gender inequality?. Personality and Social Psychology Bulletin, 28(8), 1073-1083.

Postmes, T., Spears, R., \& Lea, M. (1998). Breaching or building social boundaries? SIDEeffects of computer-mediated communication. Communication Research, 25(6), 689715.

Privitera, C., \& Campbell, M. A. (2009). Cyberbullying: The new face of workplace bullying?. CyberPsychology \& Behavior, 12, 395-400.

Richardson, K. M., \& Rothstein, H. R. (2008). Effects of occupational stress management intervention programs: a meta-analysis. Journal of Occupational Health Psychology, 13(1), 69-93

Rodríguez-Muñoz, A., Sanz-Vergel, A. I., Demerouti, E., \& Bakker, A. B. (2014). Engaged at work and happy at home: A spillover-crossover model. Journal of Happiness Studies, 15(2), 271-283.

Rösner, L., \& Krämer, N. C. (2016). Verbal Venting in the Social Web: Effects of Anonymity and Group Norms on Aggressive Language Use in Online Comments. Social Media + Society, 2(3), 2056305116664220.

Russell, J. A. (1980). A circumplex model of affect. Journal of Personality and Social Psychology, 39(6), 1161-1178.

Sanz-Vergel, A. I., Rodríguez-Muñoz, A., Bakker, A. B., \& Demerouti, E. (2012). The daily spillover and crossover of emotional labor: Faking emotions at work and at home. Journal of Vocational Behavior, 81(2), 209-217.

Sanz-Vergel, A. I., Rodríguez-Muñoz, A., \& Nielsen, K. (2015). The thin line between work and home: The spillover and crossover of daily conflicts. Journal of Occupational and Organizational Psychology, 88(1), 1-18.

Schultze-Krumbholz, A., Göbel, K., Scheithauer, H., Brighi, A., Guarini, A., Tsorbatzoudis, H., ... Smith, P. K. (2015). A comparison of classification approaches for cyberbullying and traditional bullying using data from six European countries. Journal of School Violence, 14(1), 47-65.

Selkie, E. M., Fales, J. L., \& Moreno, M. A. (2016). Cyberbullying prevalence among US middle and high school-aged adolescents: A systematic review and quality assessment. Journal of Adolescent Health, 58(2), 125-133.

Shimazu, A., Demerouti, E., Bakker, A. B., Shimada, K., \& Kawakami, N. (2011).

Workaholism and well-being among Japanese dual-earner couples: A spillover-crossover 
perspective. Social Science \& Medicine, 73(3), 399-409.

Siegel, J., Dubrovsky, V., Kiesler, S., \& McGuire, T. W. (1986). Group processes in computer-mediated communication. Organizational Behaviour and Human Decision Processes, 37(2), 157-187.

Simon, R. W. (1995). Gender, multiple roles, role meaning, and mental health. Journal of Health and Social behavior, 182-194.

Sonnentag, S., \& Binnewies, C. (2013). Daily affect spillover from work to home: Detachment from work and sleep as moderators. Journal of Vocational Behavior, 83(2), 198-208.

Spears, R., Lea, M., Corneliussen, R. A., Postmes, T., \& Haar, W. T. (2002). Computermediated communication as a channel for social resistance: The strategic side of SIDE. Small Group Research, 33(5), 555-574.

Spector, P. E. (1998). A control theory of the job stress process. In C. L. Cooper (Ed.), Theories of organizational stress (pp. 153-169). Oxford, UK: Oxford Univ. Press.

Spector, P. E., \& Fox, S. (2005). The stressor-emotion model of counterproductive work behavior. In S. Fox \& P. E. Spector (Eds.), Counterproductive Work Behavior: Investigations of Actors and Targets (pp. 151-174). Washington, DC: APA Press. Retrieved from http://doi.apa.org/psycinfo/2004-19514-007

Spielberger, C. D. (1999). State-Trait Anger Expression Inventory-2 (STAXI-2): Professional manual. Odessa, FL: Psychological Assessment Resources.

Starcevic, V., \& Piontek, C. M. (1997). Empathic understanding revisited: Conceptualization, controversies, and limitations. American Journal of Psychotherapy, 51(3), 317-328.

Story, L. B., \& Repetti, R. (2006). Daily occupational stressors and marital behavior. Journal of Family Psychology, 20(4), 690-700.

Suler, J. (2004). The online disinhibition effect. CyberPsychology \& Behavior, 7(3), 321-326.

Vaterlaus, J. M., Patten, E. V., Roche, C., \& Young, J. A. (2015). \# Gettinghealthy: The perceived influence of social media on young adult health behaviors. Computers in Human Behavior, 45,1 51-157.

Voydanoff, P. (2002). Linkages between the work-family interface and work, family, and individual outcomes: An integrative model. Journal of Family Issues, 23(1), 138-164.

Vranjes, I., Baillien, E., Vandebosch, H., Erreygers, S., \& De Witte, H. (2017). The dark side of working online: Towards a definition and an Emotion Reaction model of workplace cyberbullying. Computers in Human Behavior, 69, 324-334.

Vranjes, I., Baillien, E., Vandebosch, H., Erreygers, S., \& De Witte, H. (2018). Kicking someone in cyberspace when they are down: Testing the role of stressor evoked emotions on exposure to workplace cyberbullying. Work \& Stress, 32(4), 379-399.

Vranjes, I., Farley, S., Baillien, E., (2020). Harassment in the digital world: Cyberbullying. In S., Einarsen, H., Hoel, D., Zapf \& C. L., Cooper (Eds.). Bullying and harassment in the workplace: Developments in theory, research, and practice. (3rd ed., pp. 409-433). Boca 
Raton: CRC Press.

Walsh, K., \& Gordon, J. R. (2008). Creating an individual work identity. Human Resource Management Review, 18(1), 46-61.

Weiss, H. M., \& Cropanzano, R. (1996). Affective events theory: A theoretical discussion of the structure, causes and consequences of affective experiences at work. In B. M. Staw \& L. L. Cummings (Eds.), Research in Organizational Behavior (Vol. 18, pp. 1-74). Greenwich, CT: JAI Press.

Weiss, H. M., Suckow, K., \& Cropanzano, R. (1999). Effects of justice conditions on discrete emotions. Journal of Applied Psychology, 84(5), 786-794.

Wendorf, J. E., \& Yang, F. (2015). Benefits of a negative post: Effects of computer-mediated venting on relationship maintenance. Computers in Human Behavior, 52, 271-277.

Westman, M. (2001). Stress and strain crossover. Human Relations, 54(6), 717-751.

Westman, M., Brough, P., \& Kalliath, T. (2009). Expert commentary on work-life balance and crossover of emotions and experiences: Theoretical and practice advancements. Journal of Organizational Behavior, 30(5), 587-595.

Westman, M., \& Etzion, D. (1995). Crossover of stress, strain and resources from one spouse to another. Journal of Organizational Behavior, 16(2), 169-181.

Westman, M., \& Vinokur, A. D. (1998). Unraveling the relationship of distress levels within couples: Common stressors, empathic reactions, or crossover via social interaction?. Human Relations, 51(2), 137-156.

Wunder, C., \& Heineck, G. (2013). Working time preferences, hours mismatch and wellbeing of couples: Are there spillovers?. Labour Economics, 24, 244-252.

Xie, D., \& Xie, Z. (2019). Adolescents' online anger and aggressive behavior: Moderating effect of seeking social support. Social Behavior and Personality: An International Journal, 47(6), 1-9.

Ybarra, M. L., Mitchell, K. J., Wolak, J., \& Finkelhor, D. (2006). Examining characteristics and associated distress related to Internet harassment: findings from the Second Youth Internet Safety Survey. Pediatrics, 118(4), 1169-1177.

Yuan, Y., \& MacKinnon, D. P. (2009). Bayesian mediation analysis. Psychological Methods, 14(4), 301.

Zautra, A. J., Affleck, G. G., Tennen, H., Reich, J. W., \& Davis, M. C. (2005). Dynamic approaches to emotions and stress in everyday life: Bolger and Zuckerman reloaded with positive as well as negative affects. Journal of Personality, 73(6), 1511-1538.

Zimmerman, A. G., \& Ybarra, G. J. (2016). Online aggression: The influences of anonymity and social modeling. Psychology of Popular Media Culture, 5(2), 181-193. 


\section{Figure 1.}

The proposed relationships from daily work stressors to antisocial online behavior (AOB) in the evening mediated by anger. Dashed lines represent the crossover effects.

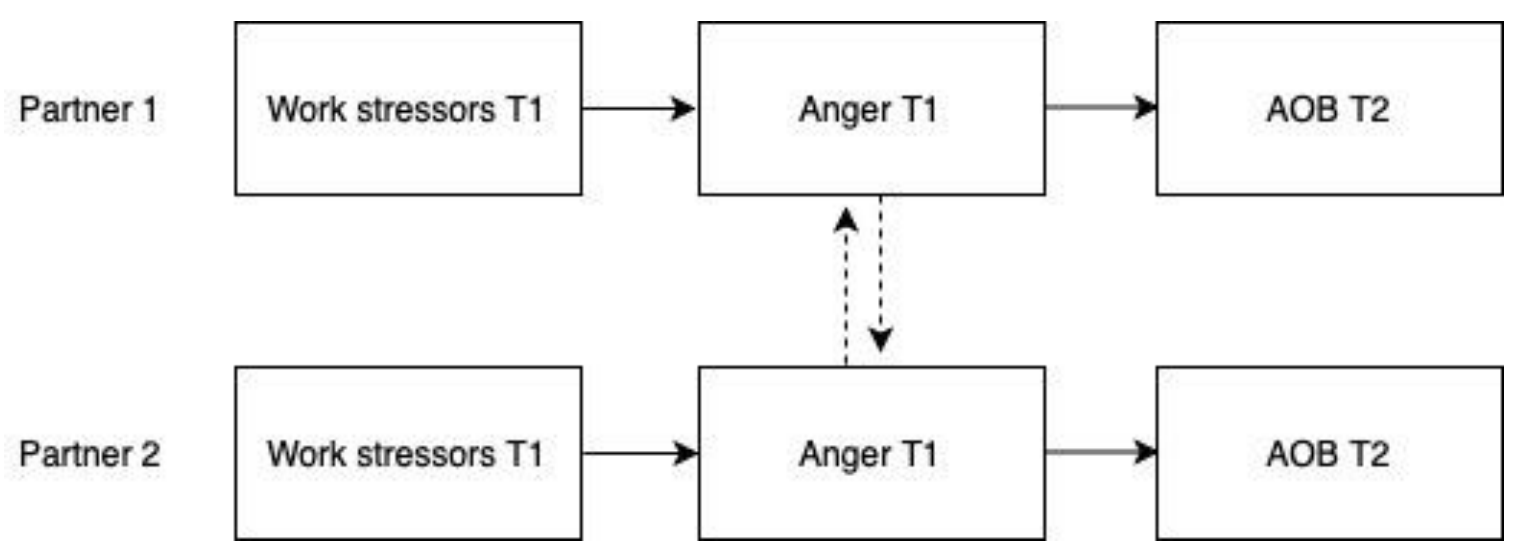


Table 1

Means, Standard Deviations and Intercorrelations Between the Study Variables

\begin{tabular}{|c|c|c|c|c|c|c|c|c|c|}
\hline & & \multicolumn{2}{|c|}{ Within-level } & \multicolumn{2}{|c|}{ Between-level } & \multirow[b]{2}{*}{1} & \multirow[b]{2}{*}{2} & \multirow[b]{2}{*}{3} & \multirow[b]{2}{*}{4} \\
\hline & & $\mathrm{M}$ & SD & $\mathrm{M}$ & SD & & & & \\
\hline \multirow[t]{4}{*}{ Men } & $\begin{array}{l}\text { 1. Time spent } \\
\text { online }\end{array}$ & 2.63 & 1.15 & 2.60 & 1.08 & - & .03 & .10 & $.14^{*}$ \\
\hline & 2. Stressors T1 & 0.93 & 1.24 & 0.91 & 0.87 & .02 & - & .06 & .04 \\
\hline & 3. Anger $\mathrm{T} 1$ & 1.30 & 0.73 & 1.26 & 0.34 & -00 & $.14 * *$ & - & $.19 *$ \\
\hline & 4. АOB $\mathrm{T} 2$ & 0.02 & 0.15 & 0.02 & 0.08 & $.16^{*}$ & .03 & .12 & - \\
\hline \multirow[t]{4}{*}{ Women } & $\begin{array}{l}\text { 1. Time spent } \\
\text { online }\end{array}$ & 2.78 & 0.94 & 2.85 & 0.79 & - & .09 & $-.20 * *$ & $.47 * *$ \\
\hline & 2. Stressors $\mathrm{T} 1$ & 1.02 & 1.18 & 1.02 & 1.00 & .05 & - & $.17^{*}$ & .02 \\
\hline & 3. Anger $\mathrm{T} 1$ & 1.31 & 0.64 & 1.24 & 0.27 & $-.15^{*}$ & $.19^{* *}$ & - & .05 \\
\hline & 4. $\mathrm{AOB} \mathrm{T} 2$ & 0.05 & 0.21 & 0.05 & 0.14 & $.25^{* *}$ & .06 & $.19 * *$ & - \\
\hline
\end{tabular}

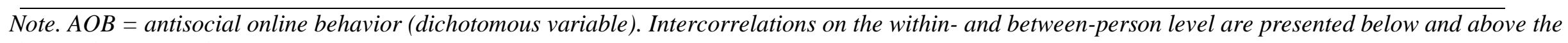
diagonal respectively. $* p<.05 * * p<.01$. 
Table 2

Results of the random intercept multilevel mediation model for men

\begin{tabular}{|c|c|c|c|c|c|}
\hline & & Estimate & $S D$ & $p$ & $95 \% \mathrm{CI}$ \\
\hline & Own effects & & & & \\
\hline & Anger T1 & & & & \\
\hline & Stressors T1 (aw) & 0.35 & 0.05 & 0.00 & {$[0.25,0.44]$} \\
\hline & $\mathrm{AOB} \mathrm{T} 2$ & & & & \\
\hline & Time online $\mathrm{T} 2$ & 0.48 & 0.10 & 0.00 & {$[0.27,0.65]$} \\
\hline & Stressors T1 & -0.06 & 0.16 & 0.71 & {$[-0.37,0.25]$} \\
\hline & Anger T1 (bw) & 0.28 & 0.12 & 0.00 & {$[0.04,0.50]$} \\
\hline & Indirect effect (aw*bw) & 0.14 & 0.06 & 0.00 & {$[0.03,0.27]$} \\
\hline $\begin{array}{l}\text { Within- } \\
\text { person }\end{array}$ & $\begin{array}{l}\text { Crossover effect } \\
\text { Anger } \mathrm{T} 1\end{array}$ & & & & \\
\hline level & Partner Anger T1 & 0.10 & 0.6 & 0.84 & {$[-0.86,1.39]$} \\
\hline & Partner Stressors T1 & -0.14 & 0.06 & 0.02 & {$[-0.25,-0.02]$} \\
\hline & AOB T2 & & & & \\
\hline & Partner Anger T1 & 0.00 & 0.15 & 0.98 & {$[-0.32,0.27]$} \\
\hline & Partner Stressors T1 & 0.01 & 0.16 & 0.94 & {$[-0.31,0.30]$} \\
\hline & $\begin{array}{l}\text { Indirect effect } 1 \\
\quad \text { (Partner stressors } \mathrm{T} 1 \rightarrow \\
\text { Partner anger T1 } \rightarrow \text { Own } \\
\text { anger } \mathrm{T} 1 \rightarrow \text { Own AOB } \\
\text { T2) }\end{array}$ & 0.01 & 0.02 & 0.84 & {$[-0.13,0.22]$} \\
\hline & $\begin{array}{l}\text { Indirect effect } 2 \\
\quad \text { (Partner stressors } \mathrm{T} 1 \rightarrow \\
\text { Partner anger } \mathrm{T} 1 \rightarrow \text { Own } \\
\text { AOB T2) }\end{array}$ & 0.00 & 0.07 & 0.98 & {$[-0.15,0.13]$} \\
\hline
\end{tabular}

\section{Own effects}

\begin{tabular}{llllll} 
& Anger T1 & & & & \\
$\begin{array}{l}\text { Between- } \\
\text { person }\end{array}$ & Stressors T1 $(\mathrm{ab})$ & 0.15 & 0.16 & 0.38 & {$[-0.18,0.43]$} \\
level & AOB T2 & & & & \\
& Time online T2 & $\mathbf{0 . 4 2}$ & $\mathbf{0 . 1 5}$ & $\mathbf{0 . 0 2}$ & {$[\mathbf{0 . 0 8 , 0 . 6 8}]$} \\
& Stressors T1 & 0.07 & 0.20 & 0.72 & {$[-0.34,0.45]$} \\
& Anger T1 (bb) & -0.06 & 0.23 & 0.80 & {$[-0.51,0.39]$} \\
& Indirect effect $(\mathrm{ab} * \mathrm{bb})$ & -0.00 & 0.10 & 0.90 & {$[-0.24,0.16]$} \\
\hline
\end{tabular}

Note. $A O B=$ antisocial online behavior. Standardized estimates are reported. Bayesian estimation was used, therefore $C I=$ Credibility Interval. Significant effects are printed bold. 
Table 3

Results of the random intercept multilevel mediation model for women

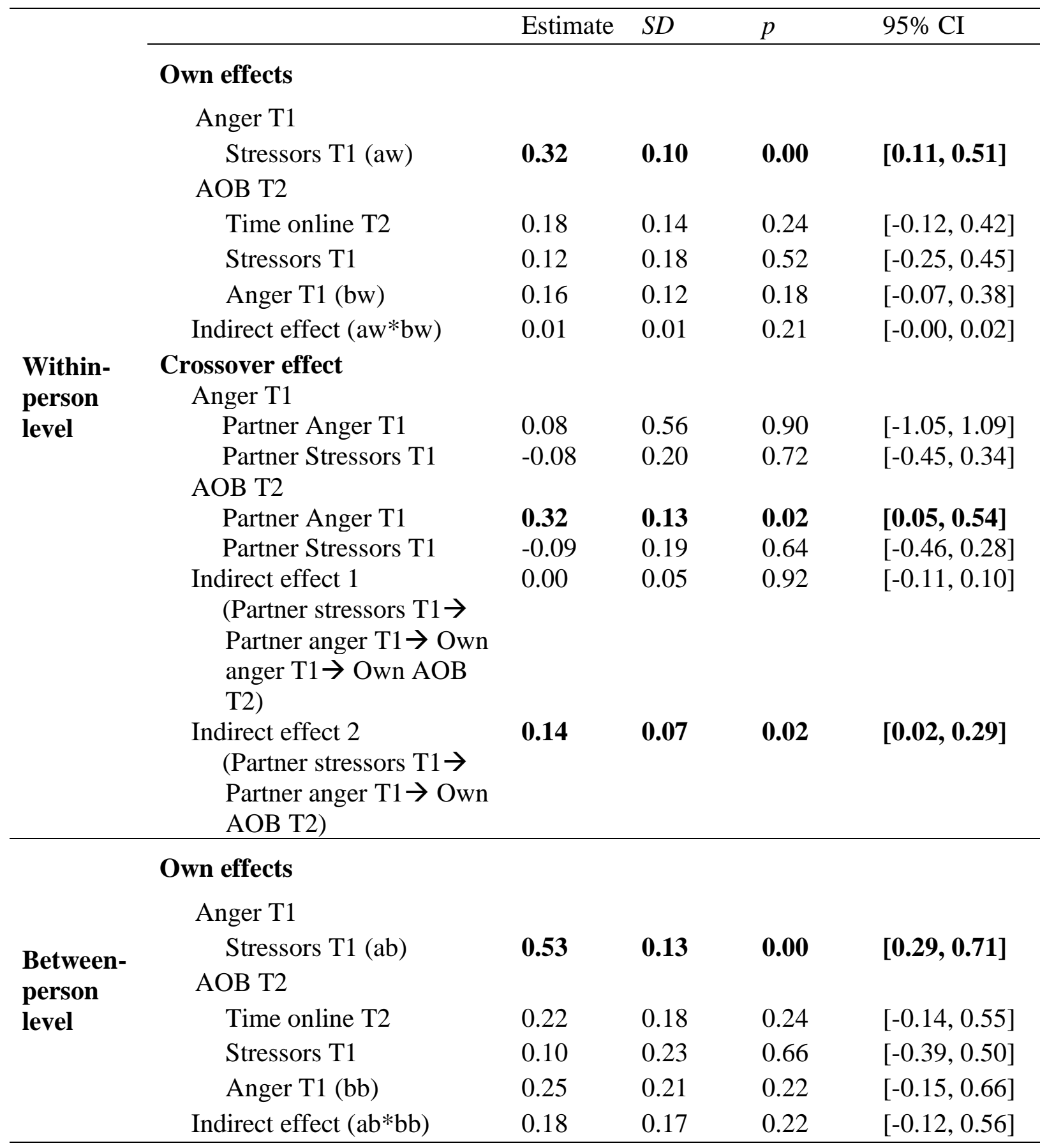

Note. $A O B=$ antisocial online behavior. Standardized estimates are reported. Bayesian estimation was used, therefore $C I=$ Credibility Interval. Significant effects are printed bold. 
